\title{
Soft-Switching High Gain Step-Up DC/DC Converter without Auxiliary Switches
}

\author{
Rajesh Thumma, K.Subdareddy, M.Vijayalaxmi, Veera Venkata Subrahmanya Kumar \\ Bhajana
}

\begin{abstract}
This manuscript presents a novel high gain, high efficiency Soft-switching high step-up DC/DC converter for battery-operated vehicles. The high step-up converter can transfer the power flow from the small voltage to high voltage. The conventional two input inductor hard switched non-isolated $D C$-DC converter improved with an additional auxiliary cell to attain the Zero voltage switching, due to obtaining the softswitching the efficiency may improve and reduces the stress across the main switches. The isolated converters are used as a transformer to attain high gain, whereas in the proposed converter obtains the high gain without a transformer and contains the high efficiency in the step-up mode of operation. The main aim of the converter is to attain the Zero voltage switching without using any additional auxiliary switches. In this paper, the input voltage applied as $30 \mathrm{~V}$, and the obtained output voltage is fifteen times to the applied voltage, which is $450 \mathrm{~V}$ and the output power $850 \mathrm{~W}$. This paper mainly presents the theoretical analysis of converter operation and the evaluation of the simulation results validated with the theoretical analysis.
\end{abstract}

Keywords- Zero voltage switching, auxiliary switches, battery backup systems.

\section{INTRODUCTION}

A non-isolated current-fed high gain, high-efficiency boost converter plays a major role in the field of batteryoperated vehicles, industrial applications, fuel cell applications. The high gain converters are more popular in electric vehicle applications because the converter doesn't consume any fuel and it is environmental friendly. Due to this the high gain, high-efficiency converters are more preferred in the field of battery-operated vehicles. The hardswitching converters are used to achieve the high gain with reduced efficiency for many applications. But the main drawback of the hard-switching converter system is, it increases switching losses by increasing switching frequency. The hard- switching converter efficiency degrades with increasing switching losses and increased with the operating frequency. The switching losses of the Hard-switching converter can be reduced with improved efficiency by adding an auxiliary resonant cell to get the soft-switching. The soft-transition DC-DC converter minimizes the transistor conducting losses by operating the supplementary resonant cell before or after the main switch goes into ON/OFF situation. There are different types of

Revised Manuscript Received on September 14, 2019.

Rajesh Thumma, Corresponding author, Dept of Electronics \& Communication Engineering, Anurag Group of Institutions, Hyderabad,Telanagana, India.(Email: rajesh.thumma88@gmail.com)

K.Subdareddy, Dept of Electronics \& Communication Engineering, Anurag Group of Institutions, Hyderabad, Telanagana, India.

M.Vijayalaxmi, Dept of Electronics \& Communication Engineering, Anurag Group of Institutions, Hyderabad, Telanagana, India.

Veera Venkata Subrahmanya Kumar Bhajana, School of Electronics Engineering, KIIT University, Bhubaneswar, Odisha, India.
DC/DC converters, where isolated and non-isolated converters are more popular in the converting the power into high to low or low to high. The isolated converters are designed with the help of the transformer and the resonant circuit to attain soft switching with high-gain. Whereas in the non-isolated converters are designed without a transformer and obtains the high gain with high efficiency. The high gain soft-switching power converter [1] is designed with the high switching frequency but the converter is operated under low power and low efficiency. The coupled inductor based soft-transition power converter system obtains the zero voltage switching using an active clamping circuit [2-3]. A non-isolated high gain power converter is operated with low input voltage and obtains the high voltage conversion ratio [4] which is 19 times the input but converter uses the eight switches to achieve the high gain. A high step-up power converter combines the harmonics plus boost resonant inverter [5] with diodecapacitor rectifier circuit to obtain the high gain by compromising the efficiency. The major drawback of the converter is very sensitive to the load. A Zero voltage transition two input boost converter [6] uses two additional diodes to get higher gain for low switching frequency with poor efficiency. A current fed soft transition converter system [7] is designed with DC/DC converter is followed by the power inverter. However, the current fed converter obtains the zero current turn-OFF for all the switches, by obtaining the soft switching the converter efficiency is increased. In addition to this, the author Md Reza Mohammadi [8] is explained the concept of a new family of ZVT buck-boost converter by adding a simple resonance cell to his proposed circuit. However, few researchers are focusing on soft-switching without adding additional auxiliary switches. The author Yong Zhang [9] is designed a circuit whose switches are operated as main and auxiliary switches to each other based on the duty cycle ratio. This converter mainly designed to eliminate the large current ripples coming in the conventional inductor based converter and achieve the soft switching using without any additional switches. In a similar way, a normal DC-DC converter is integrated with the voltage multiplier cell [10] with the coupled inductor to operate in step-up mode and to obtain the soft switching without any additional auxiliary switches. 
In this article, a novel high-gain high-efficiency boost converter is designed without using any additional switches to obtain the zero voltage turn-ON. The designed power converter is operated in different power levels to ensure the soft-switching is obtaining for all the powers. The preface of the circuit arrangement presented in section II and Section III describes the modes of operation of the converter with equivalent current flow diagrams. Section IV describes the simulated results of the designed DC/DC converter and efficiency analysis curve for different load variations.

\section{CONFIGURATION}

The proposed transformer less high gain, high step-up power converter shown in figure.1. Input inductors L1, L2 and two switches S1, S2 followed by the two snubber capacitors $\mathrm{Cr} 1, \mathrm{Cr} 2$ are the main apparatus of the designed converter. The designed converter is split into the input side and outside for ease of understanding the analysis. The power converter an input side consists of two input inductors, two main switches and the two snubber capacitors. The output side consists of resonant inductor $\mathrm{Lr}$, diodes D1, D2 and two output capacitors C1, C2 followed by the resistive load. The resonant cell is the combination of the resonant inductor, snubber capacitors. The two diodes D1, D2, are used to transmit the power to the load. The two input inductors are always maintaining the identically constant current with respect to the switching cycle. The voltage across the output capacitors are the same as $\mathrm{VC} 1=\mathrm{VC} 2$.

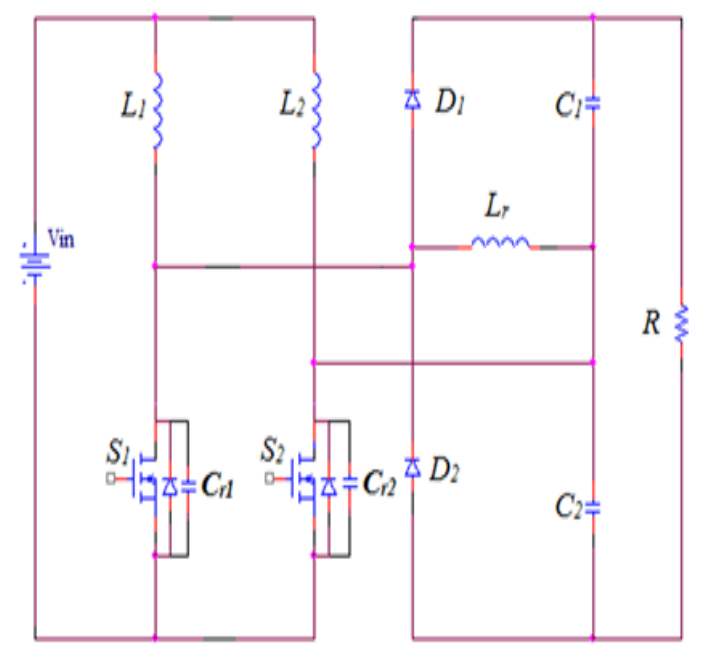

Fig1.Proposed High gain Boost DC/DC converter

\section{MODE OF OPERATION}

In Step-up mode of action the two switches are used to achieve the high gain, high efficacy with the high step upconversion without including additional auxiliary switches to attain the soft-switching. The frequency applied for the proposed converter is $50 \mathrm{kHz}$, and duty-cycle for the switches is $65 \%$ of the total time period. The designed converter is operated only in boost mode with the eight stages of intervals from to to $\mathrm{t} 7$. The key waveforms of the designed converter were shown in figure. 2 and the current flow diagrams of each operating stage are shown in figure 3.

Stage 1(t0-t1): At time $\mathrm{t} 0$, the switch $\mathrm{S} 2$ transistor is already in ON state, and the gating pulse is applied to the switch S1. After applying the gate pulse, the switch S1 will not conduct immediately, and the resonant current will flow from the antiparallel diode of the switch S1 to make the smooth switch turn on without any auxiliary switch. In this stage, the energy stored by the resonant inductor maintains the constant till the end of the interval. At the beginning of the stage, the energy stored in the two input inductors will not be the same because of the switch conduction interval are different time constants.

Stage $2(\mathrm{t} 1-\mathrm{t} 2)$ : In this time interval the switch $\mathrm{S} 1$ is moved conduction state and the switch S2 will be nonconducting. With the turn-ON of the switch S1, the current passes through the input inductor L1, due to this the energy increased in the inductor. In stage 1 the energy stored by the input inductor L2 will transfer to the output via output capacitor $\mathrm{C} 1$ to load resistor $\mathrm{R}$. The energy stored by the resonant inductor will discharge from starting of the interval $\mathrm{t} 1$, the resonant inductor reaches to negative charge to zero voltage at the end of the interval.

Stage 3 (t2-t3): At the time $\mathrm{t} 2$, the switch $\mathrm{S} 1$ current passes into the antiparallel diode of the switch S2 and the loop closes bypassing the diode current to the resonant cell. In this stage, the resonant inductor maintains the constant energy stored by the previous stage of operation.

Stage 4 (t3-t4): At the time $\mathrm{t} 3$, the gate pulse is applied to the switch S2. By applying gate pulse to the switch $S 2$, the conduction will not happen immediately due to the reverse current flowing from the antiparallel diode of the switch S2 There is no change in the resonant inductor current.

Stage 5 (t4-t5): During the time gap of $\mathrm{t} 4-\mathrm{t} 5$ the switch S2 conducts, and other switch S1 will move to a nonconducting state. Due to conduction of the switch S2 in stage 5, the current passes through the input inductor L2, due to this the input inductor accumulates the energy. The energy stored by the input inductor L1 will transmit to the output via Diode D1, output capacitor $\mathrm{C} 1$ to load resistor R. The resonant inductor stores the energy at the beginning of the interval and reaches maximum energy level to the end of the interval.

Stage 6 (t5-t6): In this stage, the resonant current flows into the antiparallel diode of the MOSFET S1 to turn-ON the switch with zero voltage transition. There is no change in the resonant inductor current.

Stage 7 (t6-t7): At this time t6, the reverse current flowing into the body diode of the $\mathrm{S} 1$, the resonant inductor maintains the constant energy which is stored in stage 5. At the end of the pulse, the switch current starts increasing from the negative to positive and switch S1 coming to conducting state and the resonant inductor current decreases towards zero after the time $\mathrm{t} 7$. 


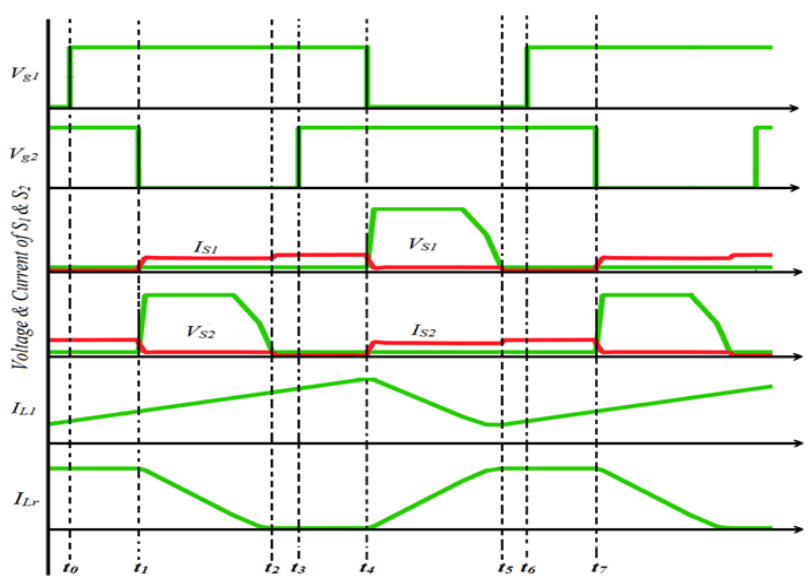

Fig.2. Key waveform of the high gain step converter

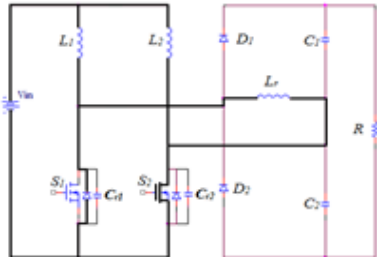

(a) Stage $1 \& .7$

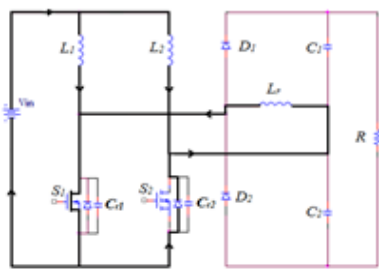

(9) Stage 3 and 4

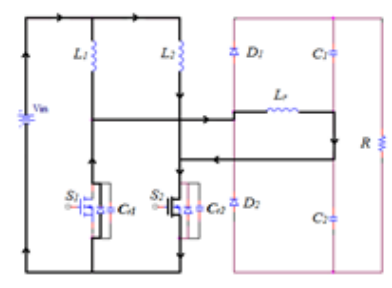

(e) Stage 6

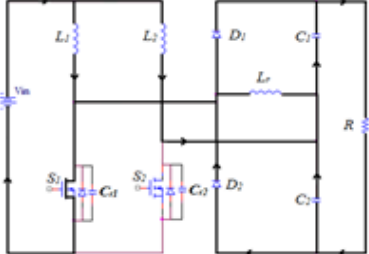

(b) Stage 2

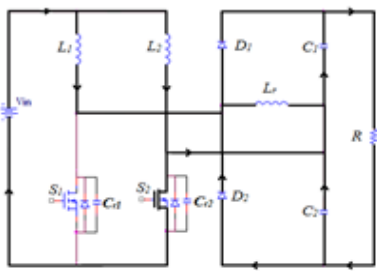

(d) Stage 5

Fig. 3 Current flow equivalent circuits of each stage

\section{SIMULATION RESULTS}

The proposed high efficiency, high gain Non-isolated Step-up DC/DC converter is designed and simulated in PLECS software tool. The simulation analysis of the step-up converter is performed. The boost converter is designed with an operating frequency of $50 \mathrm{kHz}$ with an applied input voltage of $30 \mathrm{~V}$ and the obtained output voltage is $450 \mathrm{~V}$. The major benefit of this power converter is to obtain the zero voltage switching without any auxiliary switches. The two switches are operated with a $65 \%$ duty cycle with different time cycles. Figure 4(a) and 4(b) shows the switch voltage and switch current of S1 and 4(c), 4(d) shows the switch voltage and switch current of S2. Figure. 5 shows the zero voltage turn-ON of the switches S1, S2. The load voltage and current are shown in figure 6 . The obtained load voltage is $450 \mathrm{~V}$, the load current is $1.8 \mathrm{~A}$ and the total output power obtained in simulation is $850 \mathrm{~W}$. The main advantage of this converter is getting a high step-up voltage with a minimum number of components. This article provides the simulation results of the input voltage applied as $30 \mathrm{~V}$ and the output voltage fifteen times the applied voltage which is $450 \mathrm{~V}$ and the output power $850 \mathrm{~W}$. Besides, figure 8 shows the converter simulation model using Plecs software. Figure 7 shows the efficacy curve of the designed DC-DC converter through the different load variations. This converter attains the maximum efficiency of $97.6 \%$ at the output power of $882 \mathrm{~W}$ with the output voltage $210 \mathrm{~V}$ and load resistance $50 \Omega$. This converter is simulated up to the $210 \mathrm{~V}$ to $610 \mathrm{~V}$ with the load variation from $50 \Omega$ to $500 \Omega$. Table I shows the simulated parameters of the proposed circuit. Snubber capacitors are incorporated to diminish the voltage stress across the switches and to achieve the zero voltage transition using resonant inductor and snubber capacitor.
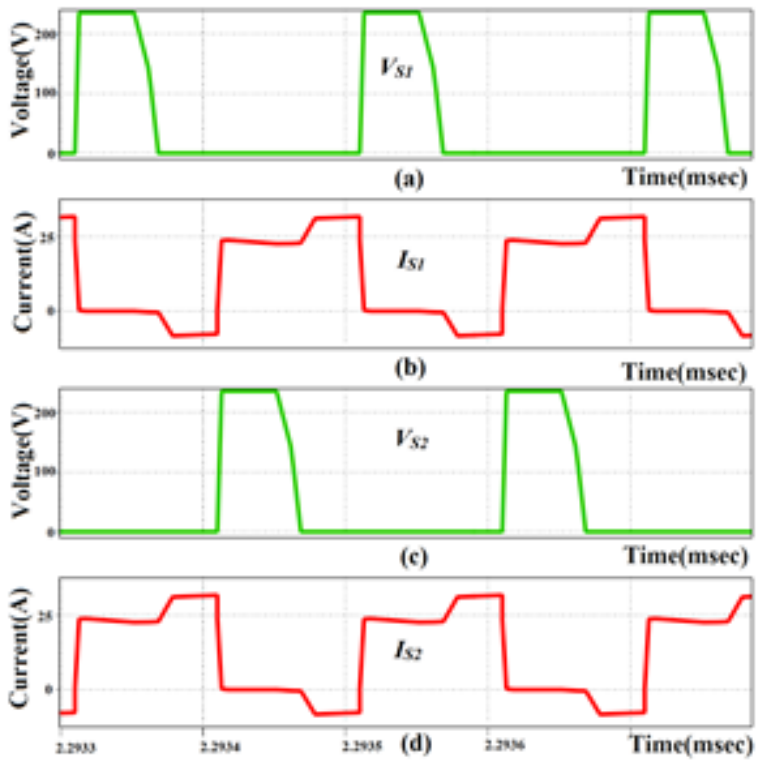

Fig.4 (a).Switch voltage of S1 (b).Switch current of S1 (C) Switch voltage of S2 (d). Switch current of S2
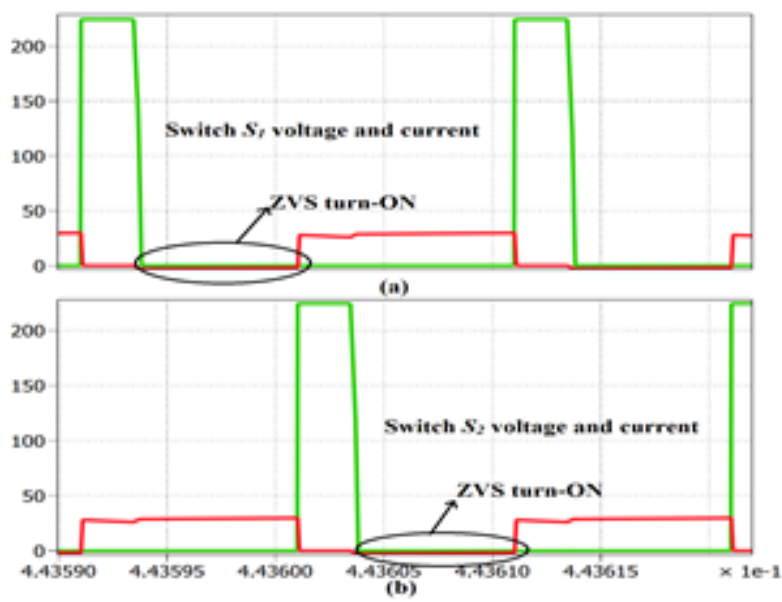

Fig.5 Zero voltage switching turn-ON for S1 ,S2 switches 


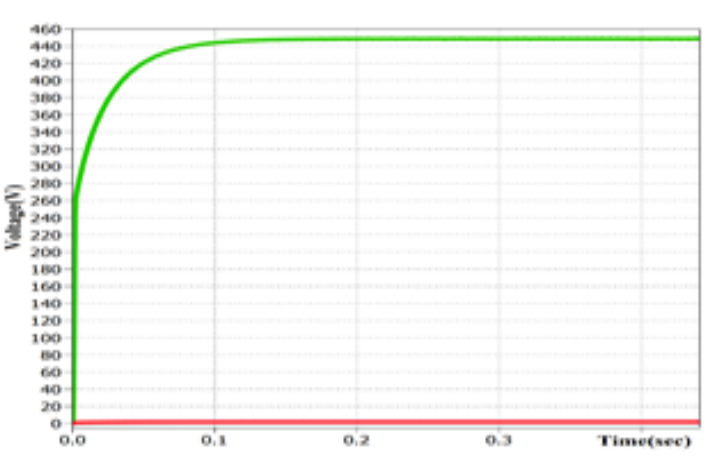

Fig. 6 Load Voltage and Load Current

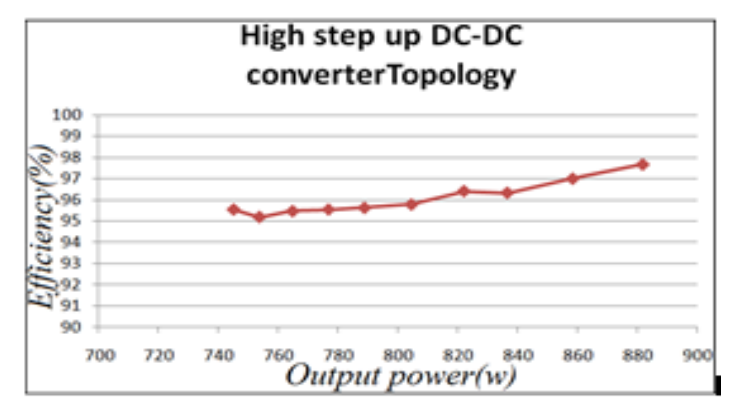

Fig. 7 Efficiency under load variations

Table I

Simulation Parameters

\begin{tabular}{|c|l|l|}
\hline S.No & Name of the component \& Symbol & Value \\
\hline 1 & Input Voltage $\left(\mathrm{V}_{\mathrm{in}}\right)$ & $30 \mathrm{~V}$ \\
\hline 2 & Input inductor $\left(\mathrm{L}_{\mathrm{t}}-4\right)$ & $170 \mu \mathrm{H}$ \\
\hline 3 & MOSFET Switches & - \\
\hline 4 & Res onant inductor $\left(\mathrm{L}_{z}\right)$ & $20 \mu \mathrm{H}$ \\
\hline 5 & Output Capacitor $\left(\mathrm{C}_{1-2}\right)$ & $470 \mu \mathrm{F}$ \\
\hline 6 & Snubber Capacitor $\left(\mathrm{C}_{31-2}\right)$ & $3 \mathrm{nF}$ \\
\hline 7 & Output Voltage & $450 \mathrm{~V}$ \\
\hline 8 & Output Power & $800 \mathrm{~W}$ \\
\hline
\end{tabular}

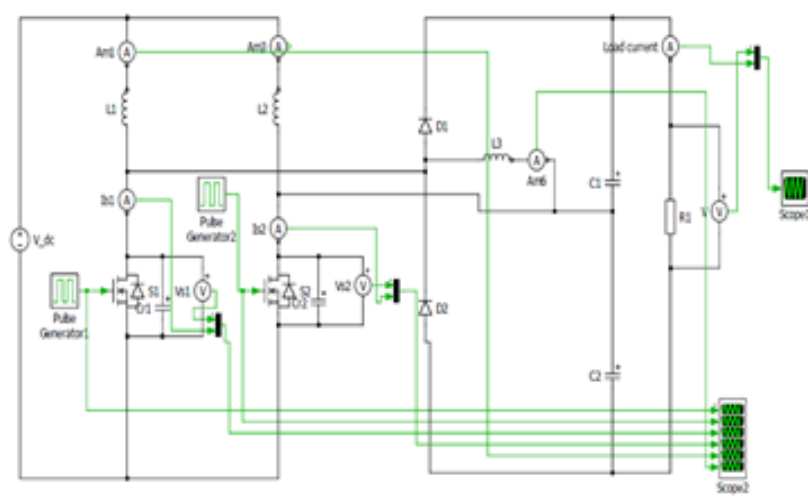

Fig. 8 Plecs model of the proposed converter

\section{CONCLUSION}

This article dealt with a new high gain, high efficacy nonisolated boost converter for battery-operated vehicles applications. The major aim of the proposed converter is to achieve the zero voltage switching without any auxiliary switches. In two switches, first one is acting as the main switch and other one acting as an auxiliary switch and vice versa. Zero voltage turn-ON is acquired for both the conducting switches. The circuit is simulated in the Plecs software with an input $30 \mathrm{~V}$ and achieves output voltage of $450 \mathrm{~V}$ with the designed converter system under $800 \mathrm{~W}$ of output power. This converter gives low output current 1.78A at $800 \mathrm{~W}$ output power. The proposed converter obtains the efficiency of $96 \%$ at $30 \mathrm{~V} / 450 \mathrm{~V}$ step-up conversion system. This converter attains the maximum efficiency of $97.6 \%$ at the load $50 \Omega$ and $210 \mathrm{~V}$ with the nearly $900 \mathrm{~W}$ output power. Therefore, the proposed system is reducing the switching losses by attaining the zero voltage turn-ON and obtains the voltage gain of 15 times to an input voltage. In future, the prototype of the converter has to design and verify with the simulation results with experimental results.

\section{REFERENCES}

1. T. Yao, C. Nan and R. Ayyanar, "A New Soft-Switching Topology for Switched Inductor High Gain Boost," in IEEE Transactions on Industry Applications, vol. 54, no. 3, pp. 2449-2458,May-June2018.

2. L. He, Z. Zheng and D. Guo, "High Step-Up DC-DC Converter With Active Soft-Switching and VoltageClamping for Renewable Energy Systems," in IEEE Transactions on Power Electronics, vol. 33, no. 11, pp. 9496-9505, Nov. 2018.

3. P. dos Santos Garcia Giacomini, J. S. Scholtz and M. Mezaroba, "Step-Up/Step-Down DC-DC ZVS PWM Converter With Active Clamping," in IEEE Transactions on Industrial Electronics, vol. 55, no. 10, pp. 3635-3643, Oct. 2008.

4. Y. Qin, Y. Yang, S. Li, Y. Huang, S. Tan and S. Y. Hui, "A High Efficiency DC/DC Converter for High Voltage Gain High Current Applications," in IEEE Journal of Emerging and Selected Topics in Power Electronics.

5. Y. Huang, S. Xiong, S. Tan and S. Y. Hui, "Nonisolated Harmonics-Boosted Resonant DC/DC Converter With High-Step-Up Gain," in IEEE Transactions on Power Electronics, vol. 33, no. 9, pp. 7770-7781, Sept. 2018.

6. K. Lee, B. Park, R. Kim and D. Hyun, "Nonisolated ZVT Two-Inductor Boost Converter With a Single Resonant Inductor for High Step-Up Applications," in IEEE Transactions on Power Electronics, vol. 27, no. 4, pp. 1966-1973, April 2012.

7. K. R. Sree, A. K. Rathore, E. Breaz and F. Gao, "SoftSwitching Non-Isolated Current-Fed Inverter for PV/Fuel Cell Applications," in IEEE Transactions on Industry Applications, vol. 52, no. 1, pp. 351-359, Jan.Feb. 2016.

8. M. R. Mohammadi and H. Farzanehfard, "A New Family of Zero-Voltage-Transition Nonisolated Bidirectional Converters With Simple Auxiliary Circuit," in IEEE Transactions on Industrial Electronics, vol. 63, no. 3, pp. 1519-1527, March 2016.

9. Y. Zhang, X. Cheng, C. Yin and S. Cheng, "Analysis and Research of a Soft-Switching Bidirectional DC-DC Converter Without Auxiliary Switches," in IEEE Transactions on Industrial Electronics, vol. 65, no. 2, pp. 1196-1204, Feb. 2018.

10. M. B. Meier, S. Avelino da Silva, A. A. Badin, E. F. R. Romaneli and R. Gules, "Soft-Switching High Static Gain DC-DC Converter Without Auxiliary Switches," in IEEE Transactions on Industrial Electronics, vol. 65, no. 3, pp. 2335-2345, March 2018. 